\title{
A propósito de las recomendaciones en urología en tiempos del covid-19
}

About the recommendations in urology in the time of covid-19

Roy R. Vásquez-Sullca, ${ }^{1, a}$, Herman Yalta-Arce ${ }^{1, b}$, Luciano Nuñez-Bragayrac ${ }^{2, c}$

\section{Señor editor,}

Frente al brote del nuevo coronavirus SARS-CoV-2 (COVID 19) que se inició en China, diversos investigadores y asociaciones científicas se han pronunciado con recomendaciones generales y específicas sobre el manejo quirúrgico durante la pandemia del COVID 19 centrándose en dos puntos: proteger al paciente con indicación quirúrgica y garantizar la seguridad del personal de salud frente al riesgo de infectarse con COVID-19 ${ }^{(1,2)}$.

La Asociación Europea de Urología debido a la pandemia ha elaborado recomendaciones para el manejo de afecciones urológicas basado en una evidencia científica incipiente debido al conocimiento aún insuficiente sobre el COVID-19 ${ }^{(2)}$. Asimismo, La Confederación Americana de Urología (CAU) y La Sociedad Peruana de Urología (SPU) también dieron recomendaciones con el objetivo de homogenizar criterios entre urólogos ${ }^{(3,4)}$.

De las recomendaciones, es importante resaltar tratamientos no quirúrgicos y aplazar la cirugías para menor exposición y priorizar recursos (ventiladores, equipos de protección personal, camas) para la atención de infectados con COVID 19 hasta el momento en que la contención disminuya el uso de estos recursos $^{(1,5)}$. De realizar una cirugía de emergencia deberá ser con todo el equipo de protección personal (EPP); en lo posible los pacientes deben contar con el examen de PCR negativo para COVID 19 y siempre una radiografía de tórax ${ }^{(2)}$. En estos tiempos donde la curva de ascenso continua, se debe optar en reducir la exposición de personal de salud al mínimo necesario para el manejo de emergencias y siguiendo las recomendaciones brindadas ${ }^{(2,5)}$.

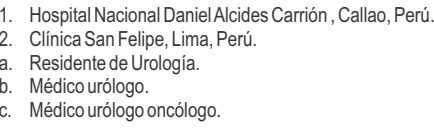

Es importante preservar la relación médico-paciente con una adecuada comunicación, principalmente en pacientes diagnosticados de neoplasias y que requieran de un tratamiento quirúrgico. El riesgo para el paciente de un tratamiento quirúrgico debe sopesar la probabilidad de quedar infectado por el COVID 19 y el riesgo de progresión de la enfermedad por una cirugía diferida ${ }^{(5)}$.

Ciertamente, debemos evitar las cirugías electivas para poder garantizar las unidades, camas y equipos al servicio de los pacientes infectados con COVID-19, en lo posterior creemos que las cirugías y las atenciones en consulta externa deberán retomarse gradualmente basándose en la logística y el nivel de resolución de cada hospital quienes deben elaborar sus protocolos de atención urológica adaptados a nuestra realidad. La telemedicina es una opción de realizar consulta en tiempos de COVID-19 siendo necesario incrementar la teleconsulta en más establecimientos del Ministerio de Salud.

Conflictos de interés: Los autores niegan conflictos de interés.

Financiamiento: Autofinanciado.

Contribución de autoría: RVS y LNB realizaron redacción y revisión del manuscrito; HYA realizó la revisión manuscrito. Todos los autores aprobaron la versión final.

\section{REFERENCIAS BIBLIOGRÁFICAS}

1. Puliatti S, Eissa A, Eissa R, Amato M, Mazzone E, Dell'Oglio P, et al. COVID-19 and Urology: A Comprehensive Review of the Literature. BJU International $2020 \mathrm{Apr}$ 6. Disponible en: https://doi.org/10.1111/bju.15071

2. Ribal MJ, Cornford P, Briganti A, Knoll T, Gravas S, Babjuk $M$ et al. European Association of Urology Guidelines Office Rapid Reaction Group: An Organisation-wide Collaborative Effort to Adapt 
the European Association of Urology Guidelines Recommendations to the Coronavirus Disease 2019 Era. Eur Urol (2020). Disponible en: https://doi.org/10.1016/j.eururo.2020.04.056

3. Confederación Americana de Urología [internet]. Posición CAU en el manejo quirúrgico de casos urológicos durante pandemia COVID-19. [citado el 06 de abril del 2020]. Disponible en: https://caunet.org/posicion-cau-en-el-manejoquirurgico-de-casos-urologicos-durantepandemia-covid-19/

4. Sociedad Peruana de Urología [internet]. Recomendaciones de prioridad de la SPU durante la pandemia del COVID-19. [citado el 04 de abril d e l $\left.\begin{array}{llll}2 & 0 & 2 & 0\end{array}\right]$. D i s p o n ible e $n$ https://spu.org.pe/pronunciamiento-spu-2020covid-19/
5. Sociedad Española de Urología [internet]. Recomendaciones en urología para paciente quirúrgico sospechoso o confirmado SARS CoV2 o COVID-19 +. [citado el 04 de abril del 2020]. D i s p o n i ble e $n$ : https://www.aeu.es/Noticias.aspx

\section{Correspondencia}

Roy R. Vásquez Sullca

Dirección: Calle los Rubíes s/n, Urbanización San Antonio. Bellavista. Callao. Perú.

Correo: roy vasquez@hotmail.com

\section{Revisión de pares}

Recibido: 07/06/2020

Aceptado: $30 / 06 / 2020$ 